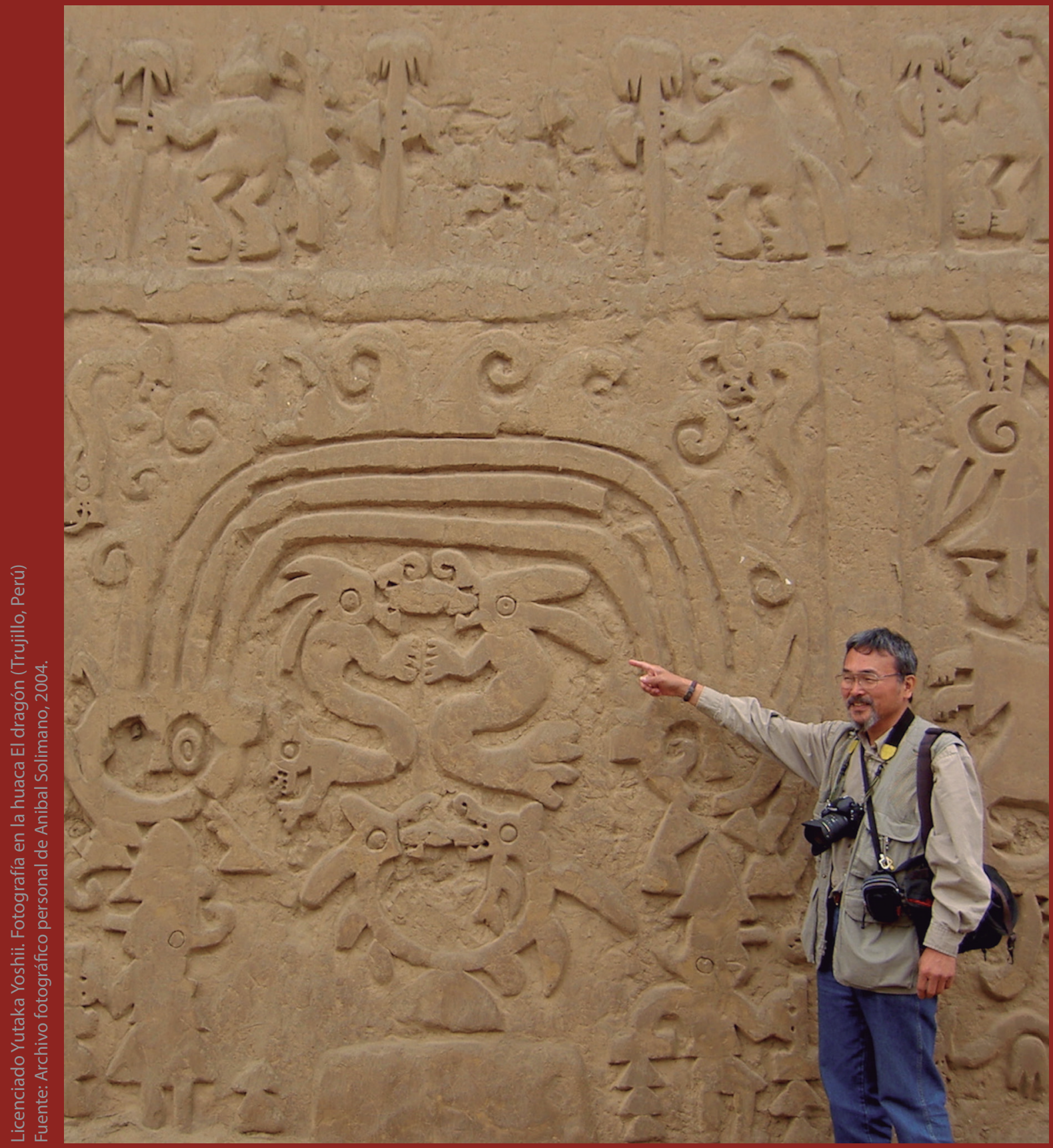

\title{
Entrevista
}

\section{Yutaka Yoshii}

Toyama, 1946. Licenciado por la Universidad Nippon\Japón, Facultad de Arte, Especialidad de Fotografía. Su trayectoria profesional ha sido desarrollada siempre cercana al patrimonio arqueológico. Es un periodista cultural con experiencia en el área de las comunicaciones gráficas y la fotografía artística especializada en piezas arqueológicas. Es miembro del Proyecto Arqueológico Sicán. También, se ha desempeñado como administrador del Museo Amano, como coordinador de diversas exposiciones museográficas sobre arqueología andina en Japón, y como corresponsal de Kyodo News y TBS TV. 
devenir Vol. 3, N5, ENERO - JUNIO 2016, PP. 181-185 - ENTREVISTA | ISSN 2312-7570

UNIVERSIDAD NACIONAL DE INGENIERÍ, LIMA

Entrevistamos al Lic. Yutaka Yoshii, experto en registro fotográfico vinculado a lo cultural, especialmente a lo patrimonial prehispánico, quien cuenta con experiencias relevantes en el marco de las investigaciones de las misiones de universidades japonesas que se vienen desarrollando en Perú desde hace varias décadas'.

\section{LH: Gracias por brindarnos un espacio de vuestro valioso tiempo... ¿Cómo se vincula vues- tro ejercicio profesional fotográfico con el Perú?}

YY: Desde que se inició mi actividad profesional en el Perú, he visto miles de piezas y sitios arqueológicos los cuales he aprendido a amar, y a mirar con respeto y fascinación. Luego de varios años y viajes por los Andes, creo que conozco parte del patrimonio cultural andino y me gusta contribuir con mi pequeño trabajo para que este sea conocido; valoro su riqueza y comprendo la necesidad de realizar un registro que transmita, con veracidad, la grandeza del pueblo que lo confeccionó, tratando de hacer que todos reconozcan en ella este valor. En esta entrevista trataré de compartir algunas de mis experiencias, que espero ayuden a quienes tengan que registrar, en una fotografía, patrimonio mueble e inmueble, como ha sido mi caso.

\section{LH: ¿Cuál cree que es la principal misión de la fotografía de patrimonio cultural?}

YY: $\quad$ Creo que tenemos la responsabilidad de transmitir con veracidad el valor de una pieza. Tal vez este ejemplo ayude a entender lo que digo: durante mi trabajo en el Museo Amano de Lima, en mis primeros años en Perú, trabajé en el proyecto de publicación de un libro sobre la colección de este museo; el investigador a cargo del libro era el profesor Yoshio Masuda, este libro formó parte de la serie Iwanami graphics. Fue un reto profesional fotografiar las piezas que veía a diario; cada pieza me provocaba una emoción diferente y, también, por que no decirlo, cierta tensión. El Museo Amano está imbuido del sentimiento de Yoshitaro Amano (el visionario japonés en reconocer la importancia de la cultura andina y el pionero en darla a conocer en Japón) por la cultura andina, y al fotografiar las piezas yo pensaba que tenía que incorporar ese sentimiento de Señor Amano. Por ello en el estudio, sentí varias veces que fotografiar las piezas era un quebradero de cabeza; sin embargo, esta experiencia fue muy importante pues, fue el punto de partida para los trabajos de fotografía que llegaron después. Luego de realizar las primeras tomas y escuchar del Señor Amano todo el valor que tenían los pueblos autores de las piezas y la dificultad y delicadeza de las técnicas y materiales utilizados por ellos y las historias que transmitían sus diseños, comprendí que lo más importante era transmitir el mundo al que pertenecían dichas piezas, este era el Mundo Andino. Ahora, cuando coloco las piezas delante de la cámara, a través del visor, las miro desde diferentes ángulos para definir el encuadre y siento que cada pieza intenta transmitir algo desesperadamente que está relacionado con aquel valor que Yoshitaro Amano reconoció y que me enseño a reconocer en este patrimonio.

Por eso empezamos a desarrollar un nuevo concepto en la fotografía de piezas arqueológicas, decidimos que era necesario fotografiar la pieza de cerámica completa para tener una idea de su forma y función, pero notamos que cuando el plano era grande los detalles importantes, las características singulares, el detalle de la técnica utilizada en su elaboración o la delicadeza o textura de sus materiales se perdían; entonces decidimos probar tomando planos más cerrados de zonas de las mismas piezas de cerámica resaltando algún diseño o técnica particular de la pieza para que los que vieran nuestras fotos tomaran mayor interés en esos detalles y a través de ellos reconozcan lo que habíamos aprendido a reconocer.

\section{LH: ¿Como fotógrafo, qué opinión le merece el patrimonio cultural peruano?}

YY: Guardo el más profundo respeto por él. Me explico a través de esta vivencia: en 1988 estaba haciendo fotografías y realizando los trámites para préstamos de 660 piezas en diferentes museos del Perú. Las piezas serían parte de la exposición "Grandes Civilizaciones Andinas", que se iba a realizar en el Museo Nacional de Etnología de Japón (conocido como'Minpaku'). Esta exposición fue planeada durante cuatro años por Tadao Umesao, entonces director de Minpaku, y Yoshio

1. Entrevista realizada el 7 de setiembre de 2015, por la Lic. Lúrica Hayakawa Coronado. 
Masuda, profesor de Universidad de Tokio. La museografía estaba a cargo de un equipo formado principalmente por los profesores Hiroyasu Tomoeda, Tatsuhiko Fujii y Norio Yamamoto, de Minpaku. La muestra tenía como objetivo dar a conocer el mérito de Yoshitaro Amano, quien fundó el Museo Amano en la ciudad de Lima para difundir las civilizaciones andinas a través de la maravillosa cultura Chancay. Yo estaba fotografiando los objetos del Museo Inka de la Universidad Nacional de San Antonio Abad del Cusco, cuando, al tercer día de iniciado mi trabajo, ocurrió un misterioso percance que paralizó mi trabajo cuando empecé a fotografiar las momias de un adulto y un niño. Para fotografiar los objetos arqueológicos alquilé una mesa pequeña y preparé un estudio de iluminación para fotografía elemental. Cuando se fotografía un objeto arqueológico grande, se coloca en el suelo un fondo de papel y encima se coloca la pieza, para luego fotografiarla. Para estas momias coloqué el fondo de papel, con el adulto mirando hacia abajo y el niño (de uno o dos años) mirando hacia arriba. De ese modo, parecía que las momias de padre e hijo estaban conversando. Con la cámara de formato medio de 6x7 marca Asahi Pentax puesta sobre un trípode que siempre utilizaba, me puse en posición de fotografiar. Regulé un poco la iluminación y presioné el disparador, pero extrañamente no funcionaba. Varias veces apreté el disparador y no sentí en mi dedo la presión habitual del dispositivo. Sentía que presionaba el disparador al vacío y no se activaba el sistema de obturación. Por lo general, cuando se presiona el disparador inmediatamente se levanta el espejo interno, se abre la cortinilla y la imagen se graba en la película. Esto dura aproximadamente 1/30 segundos. El sonido característico que produce la activación de este sistema de obturación tiene dos tiempos, el comienzo y el final, es decir, cuando se cierra la cortinilla y se baja el espejo nuevamente, con lo cual finaliza la toma fotográfica. Esa vez no hubo sonido y no sentí en mi dedo la sensación de haber disparado. Esta cámara utilizaba baterías de litio CR123, que duraban hasta para 30 rollos de 10 tomas cada uno. Pensé que las baterías se habían gastado y coloqué unas nuevas, pero no hubo reacción. Por segunda vez puse otro juego de baterías y tampoco cambió la situación. Quité entonces la cámara del trípode para disparar hacia otro lado, y el problema subsistía. Desistí con la cámara de medio formato y saqué una cámara más pequeña, de $35 \mathrm{~mm}$ marca Nikon, modelo F3. Intenté disparar antes de adherirla al trípode, y no podía creerlo: tampoco funcionaba. Esta cámara tenía un sistema mecánico y no utilizaba baterías. Tampoco funcionaba el disparador. Los curadores del Museo Inka que me estaban apoyando se quedaron en silencio. El ambiente del lugar se tornó pesado y oscuro, y parecía impregnado de los ancestrales sentimientos que provenían de las momias. Finalmente, no pudimos descubrir las causas de que las cámaras no funcionaran, y dejamos de trabajar ese día. Al día siguiente seguía preocupado, pero probé las cámaras y me di con la sorpresa de que funcionaban como si nada hubiera pasado. Al fotografiar, cuando escuchaba el sonido del sistema de obturación, me sentía bien. Con el dedo en el disparador sentí la presión de siempre. Nunca entendí qué pasó aquel día. En todo caso, me pregunté si había faltado el respeto a las momias al ponerlas en una forma determinada. Por ello, siempre realizo mi trabajo con mucho respeto por las piezas que fotografío, más aún si son restos humanos.

No creo en la existencia de los espíritus; sin embargo, ese fue uno de los días más extraños de mi vida. Desde entonces, antes de fotografiar los objetos o lugares de los antiguos habitantes de los Andes, siento una tensión que no puedo explicar. Por ello, empecé a acercarme a la mirada y pensamientos de los antiguos pobladores de los Andes, para saber qué los puede molestar, y nunca más tuve problemas parecidos.

\section{¿Cuál es el método que utiliza para el registro fotográfico arqueológico?}

Pues implementamos un método de registro fotográfico, efectivamente. Alrededor de 1984, me encontré en el Museo Amano con el antropólogo japonés Kazuo Terada, que presidía la misión de Estudios Arqueológicos de Centroamérica y los Andes de la Universidad de Tokio. Él me pidió que enseñara a tomar fotografías de los fragmentos de cerámica extraídos de una excavación de la misión, con la indicación de poner mayor contraste sobre la superficie de la cerámica, de forma que permitiese reconocer la textura de esta o de la decoración, resaltándola. No obstante, había un problema: la iluminación no debería provocar sombra ni contraste en la superficie sobre la que se colocaban los fragmentos. 
La mayoría de los fragmentos que la misión investigaba pertenecían a la época formativa y tenían diseños de líneas talladas con poca profundidad. La mayoría de los fragmentos de cerámica eran de color marrón y ocre, y algunos negros. Para fotografiar la superficie era necesario poner contrastes. Desde el lugar de la excavación se traían cientos de fragmentos que ordenaban los jóvenes estudiantes de la misión.

Primero, tuve conversaciones para preparar el trabajo de fotografía. Luego, quedamos en clasificar los fragmentos a fotografiar por tamaño, pues cuando las piezas son de tamaños muy dispares, se pierde el detalle en las piezas más pequeñas. En cada encuadre no es recomendable colocar más de diez fragmentos, pues podría perderse el detalle de cada uno y no se les resaltaría debidamente. Por eso, quedamos en colocar de seis a ocho fragmentos en cada encuadre para registrar la información importante que contienen las cerámicas de la época formativa. Colocamos escalas de $5 \mathrm{~cm}$ dentro de los encuadres de las fotografías para tener una referencia exacta del tamaño real de los fragmentos de cerámica, tal como se suele realizar en todas las misiones de estudios para tener medidas exactas o referenciales. Con todo preparado, empecé a enseñar las maneras de fotografiar colocando sombras sobre fragmentos, pero no al fondo. Para ello preparamos un marco de madera de $50 \mathrm{~cm} 2$ y colocamos una placa de vidrio como base. Sobre ella pegamos papel cebolla. También se puede utilizar vidrio pavonado; sin embargo, en ese caso también es necesario cubrir el vidrio con papel cebolla para proteger el vidrio y los fragmentos. Es fácil cambiarlo cuando se ensucia. Básicamente se utiliza luz solar, luz de exteriores. Se coloca la cámara de tal manera que quede en paralelo con los fragmentos. Se usa una iluminación artificial tipo diurna de $500 \mathrm{~W}$ con un ángulo de 45 grados desde arriba del visor de la cámara. Se acomoda el encuadre para que las sombras de las líneas talladas de los fragmentos de la imagen sean evidentes luego de fotografiarlas, y que esta salga debajo del visor. Para que no salga la sombra de mismo fragmento en la imagen, colocamos una iluminación tipo diurna de $500 \mathrm{~W}$ dentro del marco de madera. Cuando la iluminación dentro del marco es débil, se hace notoria la sombra de los fragmentos encima del papel cebolla. Cuando la iluminación es muy fuerte, no se nota el contorno. Utilizando varios papeles se puede regular la fuerza de iluminación, y una vez que se termina de colocarlos no es tan difícil hacer la fotografía. El lente utilizado para este trabajo fue uno de 50 $\mathrm{mm}$ macro. Este lente de fotografía es el más importante de los implementos necesarios para una buena foto. Desde entonces, la misión hizo sus fotos de acuerdo con el método que yo enseñé para preparar sus informes de investigación. Esta es la historia de mi respuesta a la tarea que me dio el profesor Terada. Sin embargo, ahora se pueden modificar y editar las imágenes utilizando Photoshop, lo cual elimina la molestia de tener que hacer desaparecer la sombra del fondo.

\section{¿Podría contarnos de un registro fotográfico de campo en nuestros Andes?}

Claro que sí. En 1987 conocí a Izumi Shimada (arqueólogo de origen japonés formado en los Estados Unidos de Norteamérica). Llegar desde Chiclayo hasta Batán Grande tomaba una hora aproximadamente en auto, recorriendo una carretera no pavimentada. En esa época, Batán Grande era un sitio concurrido por ser parte de la cooperativa de caña de azúcar. La misión de los estudios científicos de Sicán alquiló la vieja casona de un exhacendado como un lugar de concentración.

Un día cualquiera de trabajo empezaba a las 7 de la mañana, cuando partíamos; en 40 minutos aproximadamente llegábamos al lugar de excavación. El Sr. Shimada preparaba los desayunos y los sándwiches de todos para llevar al lugar de trabajo en el campo. A las 11:30 a.m. aproximadamente, se suspendía el trabajo bajo el sol y tomábamos un descanso. Los trabajadores empezaban a comer su refrigerio, mientras los miembros de la misión arqueológica comían los sándwiches y una fruta para mitigar un poco el hambre.

La excavación terminaba a las 3 de la tarde. Antes de regresar, hacíamos una parada en el pozo común de agua de la comunidad Zaranda, donde nos bañábamos. A las 5 de la tarde recién almorzábamos la comida preparada por la cocinera. A las 7 de la noche otra vez todos llegaban al comedor y empezaba el seminario del Sr. Shimada. Los estudiantes presentaban un informe de la situación de cada excavación, incluyendo posibilidades y pronósticos, en el caso de los peruanos en inglés y de los americanos en español. Todos los sábados se hacía una presentación a todos los investigadores del equipo de los avances de la semana. 
La excavación de materiales tan importantes es lenta por ser detallada; el registro fotográfico de campo consiste en fotografiar cómo van apareciendo los objetos, tratando de evidenciar su orden espacial y su estado para el posterior uso de este registro en el análisis de los contextos, en la restauración y en la conservación de las piezas. Para ello utilizábamos cámaras réflex Nikon $\mathrm{F} 3$, con diversos lentes, y en un solo día podíamos utilizar hasta quince rollos de diapositivas. En el registro arqueológico de campo se empleaban las diapositivas, pues estas tienen una mejor calidad para la impresión y permiten que el investigador las use en sus conferencias. Sin embargo, todo esto ya quedo atrás debido al uso de cámaras digitales. Había que tener mucho cuidado con las cámaras fotográficas, pues pese a tener la facilidad diaria de limpieza utilizando un spray de aire, por ser cámaras mecánicas (algo imposible con las digitales), estas se deterioran con la cantidad de tierra a la que son expuestas en una excavación que se realiza a 12 metros de profundidad con una constante remoción de tierra.

A partir del año 2006 empecé a utilizar cámaras digitales de manera paralela con las cámaras mecánicas; ya en el año 2008 tuve que utilizar solo las cámaras digitales, pues no se encontraba rollos de película con facilidad, y era muy difícil revelarlos.

Yo extraño las cámaras mecánicas; cuando las utilizaba yo podía controlar el resultado completamente. Aun cuando tomo fotografías en el modo mecánico, con las cámaras digitales siempre hay una variación del color y la realidad puede ser alterada, lo cual no sucede con las cámaras mecánicas, con estas últimas siempre hay un reto por lograr la mejor toma utilizando los conocimientos fotográficos; esto involucra pensar y desarrollar creatividad y sensibilidad frente a los objetos, lo cual se va perdiendo un poco con las cámaras digitales.

Gracias al descubrimiento de la gran tumba de Huaca Loro, se realizó la "Exposición arqueológica de la cultura Sicán" en 1994 en el Museo Nacional de Ciencias de Japón. Durante dos años esta exposición recorrió doce ciudades de Japón, pese a que en aquella época la cultura Sicán era desconocida. Al final se registraron más de un millón de visitantes japoneses. En esta exposición no se exhibieron las piezas de las antiguas civilizaciones de los Andes como piezas de arte, sino que se difundieron imágenes televisivas de las excavaciones, y como resultado de este trabajo se pudo realizar la exposición. Por ello atrajo la simpatía de muchas personas.

He fotografiado el proceso de excavación de Sr. Shimada, el trabajo de restauración y las piezas de hace 1000 años. Además, después de la "Exposición arqueológica de la cultura Sicán", he trabajado como coordinador para la realización de varias muestras como "Exposición de la cultura Moche" (1999-2000), "Exposición de la cultura Maya" (2003-2004), "Exposición de la cultura Nazca" (2009-2010), “Exposición de la cultura Inca, Maya y Azteca” (2007-2008), “Exposición de la cultura Sicán" (2009-2010) y “Exposición de la cultura Inca” (2012-2014).

\section{¿Tiene alguna reflexión final que desee alcanzarnos?}

No es fácil acercarse al pensamiento de los creadores antiguos... Incluso siento miedo de esa época. Si tomo fotografías de los objetos antiguos con un sentimiento débil, la foto será débil. Si tomo una foto con sentimiento firme, esa firmeza se transmitirá a la imagen de la pieza.

Creo que la fotografía como método de expresión tiene una posibilidad ilimitada. La fotografía es testigo de historia, registradora de tiempos, acusadora de circunstancias y creadora de futuros. 